\title{
Behaviors of neodymium isotopes and carbon isotopes in the South Atlantic Ocean
}

\author{
Ruixue WANG ${ }^{1 *}$, AleXANDER M. PiOtrowski ${ }^{1}$, \\ JOSEPHINE A. CLEGG ${ }^{1}$, GIDEON M. HENDERSON ${ }^{2}$
}

${ }^{1}$ Department of Earth Sciences, University of Cambridge, Cambridge, CB2 3EQ, UK (*correspondence: rw581@cam.ac.uk)

${ }^{2}$ Department of Earth Sciences, University of Oxford, Oxford, OX1 3AN, UK

Changes in deep ocean circulation play a major role in climate change due to heat transportation and large carbon storage in the deep ocean. The South Atlantic Ocean is a key area for monitoring changes in the global overturning circulation intensity. Two proxies which have been used to infer water mass sourcing and mixing proportions are stable carbon isotopic composition $\left({ }^{13} \mathrm{C} /{ }^{12} \mathrm{C}\right.$, expressed as $\left.\delta^{13} \mathrm{C}\right)$ and neodymium isotopic composition $\left({ }^{143} \mathrm{Nd} /{ }^{144} \mathrm{Nd}\right.$, expressed as $\varepsilon N d)$. To better understand the sensitivity of these two proxies to past changes in ocean circulation, and determine what processes cause their decoupling, their distribution in the modern deep ocean needs to be clarified.

Here we present the first profile of dissolved neodymium isotopes alongside carbon isotopes of dissolved inorganic carbon measured on the same seawater samples across a longitudinal section at $40^{\circ} \mathrm{S}$ in the South Atlantic (GEOTRACES section GA10). The results show the different behaviors of the two elements and their isotopes between the upper ocean $(<2500 \mathrm{~m}$ depth $)$ and the deep ocean $(>2500 \mathrm{~m}$ depth). Our data highlight the quasi-conservative behavior and covariation of $\mathrm{Nd}$ and $\mathrm{C}$ isotopes in the deep ocean, indicating the high reliability of the two proxies for palaeoocean circulation in the South Atlantic. We also examine nonconservative behaviors in the upper ocean from a reversible scavenging perspective and discuss the implications regarding changes in vertical transport of geochemical signals with varying particle flux. 